\title{
Scalable, Large-Area Printing of Pore-Array Electrodes for Ultrahigh Power Electrochemical Energy Storage
}

\author{
Sang Ho Lee,*i) Colin Johnston, and Patrick S. Grant \\ Department of Materials, University of Oxford, Oxford OX1 3PH, U.K. \\ Supporting Information
}

ABSTRACT: Through-electrode thickness honeycomb architectures were layer-by-layer self-assembled directly through a scalable printing process for ultrapower hybrid lithium-ion capacitor applications. Initially, the electrochemical performance of the pore-array electrodes was investigated as a function of the active material type (graphene plates, carbon nanofibers, and activated carbon). Inactive components (conductive carbon and polymer binder) were then minimized to $5 \mathrm{wt}$ $\%$. Finally, an optimized activated carbon-based cathode was paired with a spray-printed $\mathrm{Li}_{4} \mathrm{Ti}_{5} \mathrm{O}_{12}$-based anode and a range of anode-to-cathode mass ratios in a lithium-ion capacitor
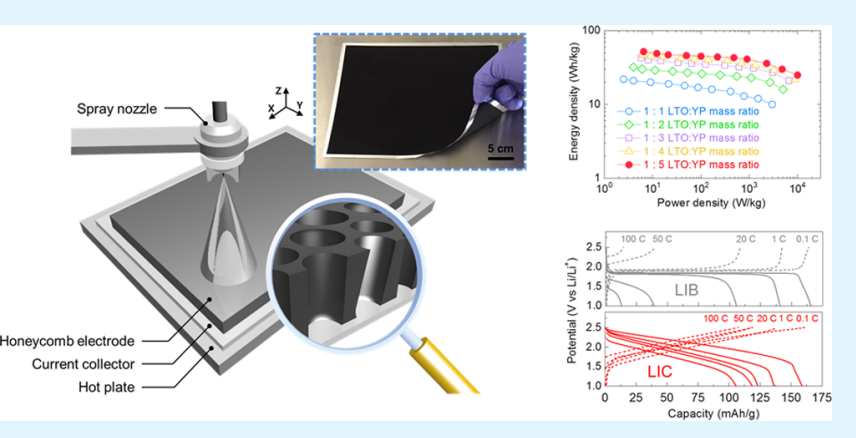
arrangement were investigated. A 1:5 anode/cathode mass ratio provided an attractive energy density comparable with a $\mathrm{Li}_{4} \mathrm{Ti}_{5} \mathrm{O}_{12} / \mathrm{LiFePO}_{4}$ lithium-ion battery but with outstanding power capability that was an order of magnitude greater than typical for lithium-ion batteries. The pore-array electrode was reproduced over areas of $20 \mathrm{~cm} \times 15 \mathrm{~cm}$ in a double-sided coated configuration, and the option for selectively patterning electrodes was also demonstrated.

KEYWORDS: pore array, spray printing, graphene, carbon nanofiber, YP-50F, $\mathrm{Li}_{4} \mathrm{Ti}_{5} \mathrm{O}_{12}$, lithium-ion capacitor

$\mathrm{D}$ riven by the increasing worldwide requirement for more sustainable energy systems such as renewable generation and storage, the need to replace internal combustion engines with electric drivetrains and the trend for lighter, thinner portable electronics including laptops and mobile phones, the rechargeable lithium-ion battery (LIB) has come to dominate the energy-storage market. The dominance arises from the LIB's excellent gravimetric and volumetric capacity $(200-300 \mathrm{Wh} / \mathrm{kg}$ and $600-1000 \mathrm{Wh} / \mathrm{L}$, respectively), a relatively high operating voltage $(\sim 4 \mathrm{~V})$, low self-discharge, and a continued reduction in cost. $^{\text {P-4 }}$ Nonetheless, its relatively poor power performance $(300-400 \mathrm{~W} / \mathrm{kg})$, which is almost 2 orders of magnitude lower than that of electrochemical double-layer capacitor (EDLC) cells $(10-20 \mathrm{~kW} / \mathrm{kg}),^{5-7}$ remains a weakness for some applications, particularly for public transport vehicles, heavy machinery, and some applications in the defense and aerospace industry.

Lithium-ion capacitor (LIC) devices ${ }^{8-10}$ aim to combine the high capacity of LIBs and the high power of EDLCs. In a general LIC configuration, an insertion-type electrode is paired with a high-surface-area carbon electrode, with the system immersed in a standard LIB electrolyte. Although conventional lithiation/ delithiation reactions take place at the negative electrode, delivering an attractive capacity (much higher than EDLCs but lower than LIBs), the carbon positive electrode stores electric energy by quickly forming a reversible electrical double layer at the interface between the electrode and the electrolyte, offering fast electrode kinetics and a cycle life superior to LIBs. However, because positive and negative electrode processes must remain in charge balance, the overall performance is a compromise between that of a LIB and an EDLC. To realize the potential advantages of LICs more fully, a less-comprised balance of power and capacity is needed that better preserves the energy density of LIBs and the power performance and cycle stability of EDLCs.

Porous or hollow structures at the meso- or a few micron-scale increase active surface area and promote faster electrode reaction dynamics. ${ }^{11,12}$ Unfortunately, relatively sophisticated and expensive processes are often required to fabricate these porous structures, ${ }^{13,14}$ inhibiting their scalability and applicability.

We explore a spray-printing approach to fabricate higherperforming LIC electrode configurations, which has previously been shown to be effective in fabricating novel LIB and EDLC electrode arrangements, including high density graded architectures and multilayer arrangements ${ }^{15-17}$ in a diverse range of materials that includes $\mathrm{TiO}_{2}(\mathrm{~B}), \mathrm{Si} / \mathrm{SiO}_{x}, \mathrm{TiO}_{2}, \mathrm{Fe}_{2} \mathrm{O}_{3}$, carbon nanofibers, and $\mathrm{LiFePO}_{4}$ (LFP). ${ }^{18-21}$ Here, the focus is on the production of large-area pore arrays for LIC electrodes. By controlling the drying behavior of the electrodes on heated current collectors, the electrode porosity was controlled reliably over large-area electrodes that showed improved gravimetric

Received: August 13, 2019

Accepted: September 25, 2019

Published: September 25, 2019 
and volumetric densities at high charge/discharge rates $(\geq 4000$ $\mathrm{mA} / \mathrm{g}$ ) when compared with conventional equivalents manufactured by slurry casting.

Through-thickness pore-array positive electrodes for a LIC are fabricated by spray printing using either graphene plates (GP), carbon nanofibers (CNF), or commercial activated carbon YP-50F particles (YP). The electrochemical performance of the resulting electrodes is investigated along with the effects of conductive carbon enhancer (Super P, SP) and polymeric binder (carboxymethyl cellulose, CMC). A bestperforming pore-array YP-based cathode electrode is coupled with a spray-printed $\mathrm{Li}_{4} \mathrm{Ti}_{5} \mathrm{O}_{12}$ (LTO) negative electrode in a LIC configuration that delivered a stable energy density of $\sim 55$ $\mathrm{Wh} / \mathrm{kg}$ at $\sim 0.1 \mathrm{C}$ and an outstanding power density of $\sim 10000$ $\mathrm{W} / \mathrm{kg}$ at $\sim 450 \mathrm{C}$. The scalability of the through-thickness porearray electrode $(\sim 20 \mathrm{~cm} \times 15 \mathrm{~cm})$ and the possibility to assemble the pore-array structure selectively in a specific region of the electrode are also demonstrated. We conclude that the spray-printing approach may offer a credible route to manufacture anodes and cathodes with novel functionality (pore arrays and selective patterning) that provide a larger design space to balance energy and power requirements in electrochemical energy-storage devices.

\section{RESULTS AND DISCUSSION}

The scheme illustrated in Figure 1 describes the self-assembly of through-thickness pore-array electrodes directly on a large-area

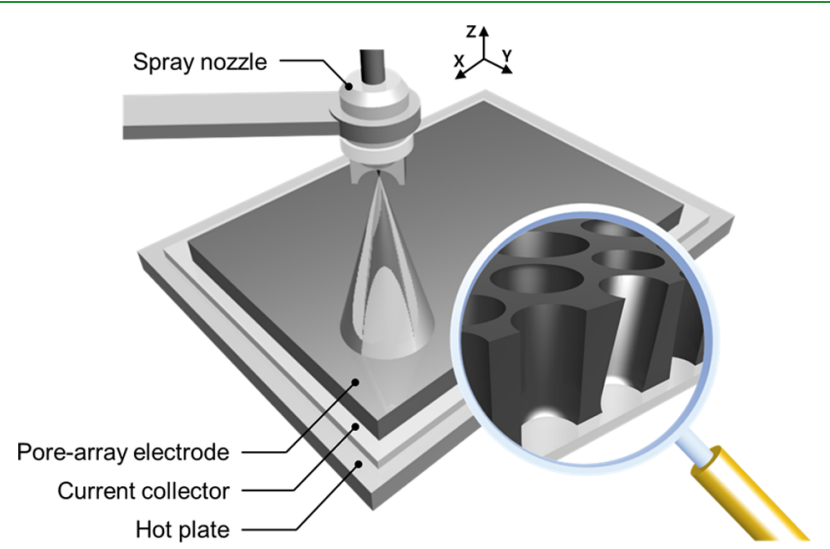

Figure 1. Graphical illustration of the spray-printing process for porearray electrodes directly on current collectors. The inset cartoon shows an idealized morphology of through-thickness directional pore channels to promote lithium-ion mobility.

substrate by a variant of a spray-deposition or spray-printing process, which atomizes and deposits a slurry-based suspension. Active carbon materials (GP, CNF, or YP), SP, and CMC were dispersed in a fugitive bisolvent with an optimum deionized water to isopropyl alcohol (DI/IPA) volume ratio of 50:50 that provided a rheologically stable and low viscosity suspension suitable for pumping to a spray head and then continuous atomization into droplets. The droplets were propelled by the atomizing gas onto the heated current collector $\left(>120{ }^{\circ} \mathrm{C}\right)$, which enabled the fast, effective evaporation of bisolvent carriers in each of the printed layers. A pore-array structure was spontaneously formed during drying that propagated from the current collector and which was maintained as subsequent layers were added, ${ }^{21,22}$ as described in the magnified cartoon in Figure 1. The zig-zag movement of the spray head in a preprogrammed $x$ - and $y$-direction pattern for multiple cycles allowed the fabrication of the pore-array structure over large areas (typically $>20 \mathrm{~cm} \times 15 \mathrm{~cm}$ ) and control of electrode thicknesses up to hundreds of microns.

Figure $2 \mathrm{a}-\mathrm{c}$ shows scanning electron microscope (SEM) images of the surface of a series of pore-array electrodes based on either GP, CNF, or YP, respectively. Here, all electrodes contained the active carbon material, SP, and CMC in a mass ratio of 80:10:10. The pore-array electrodes had pores of $20 \pm 9$ $\mu \mathrm{m}$ diameter that were separated by interconnected pore-array cell "walls" of thickness $10-20 \mu \mathrm{m}$. The insets in the right corner of Figure $2 \mathrm{a}-\mathrm{c}$ magnify the region of the active carbon material, showing $\sim 2 \mu \mathrm{m}$ size GP, $\sim 100 \mathrm{~nm}$ diameter $\mathrm{CNF}$, and $\sim 5 \mu \mathrm{m}$ size $\mathrm{YP}$, respectively. Figure $2 \mathrm{~d}-\mathrm{f}$ shows the corresponding electrode cross-sections, with the layer-by-layer formation of through-thickness pore structures, as highlighted by yellow dotted lines. As shown in the previous work, ${ }^{20,21}$ these oriented pores can provide benefits in terms of facilitating lithium-ion mobility and effective electrode/electrolyte contact, offering an improvement in capacity and most particularly rate performance. All of the electrodes were $\sim 20 \mu \mathrm{m}$ thick (see Table 1), and thicker electrodes were studied subsequently.

The electrochemical behavior of the electrodes was examined through cyclic voltammetry $(\mathrm{CV})$ in the scan rate range of $0.05-$ $50 \mathrm{mV} / \mathrm{s}$, as shown in Figure $3 \mathrm{a}-\mathrm{c}$. Here, the pore-array electrodes were combined with $\mathrm{Li}$ metal foil counter electrodes in a coin-cell configuration. All of the electrodes displayed quasirectangular CV curves at increasing scan rates, which is typical of electrochemical double-layer capacitance. ${ }^{23,24}$ Progressive increases in the scan rate to $50 \mathrm{mV} / \mathrm{s}$ resulted in a progressive increase in current density for all of the electrodes. However, the difference in the anodic/cathodic current density at increasing scan rates became more marked, depending on the active carbon material, as shown in Figure $3 \mathrm{a}-\mathrm{c}$. The specific capacitance $C$ $[\mathrm{F} / \mathrm{g}]$ was estimated from the $\mathrm{CV}$ curves according to ${ }^{25,26}$

$$
C=\frac{1}{m \nu\left(V_{\mathrm{a}}-V_{\mathrm{c}}\right)} \int_{V_{\mathrm{a}}}^{V_{\mathrm{c}}} I(V) \mathrm{d} V
$$

where $m$ is the total electrode mass $[\mathrm{g}], \nu$ is the scan rate $[\mathrm{V} / \mathrm{s}]$, $V_{\mathrm{a}}-V_{\mathrm{c}}$ is the potential window $[\mathrm{V}]$, and $I$ is the charging or discharging current $[\mathrm{A}]$. In the arising capacitance plots (Figure $3 \mathrm{~d})$, the pore-array YP-based electrode had the highest capacitance at all rates, for example, $\sim 62 \mathrm{~F} / \mathrm{g}$ at $0.05 \mathrm{mV} / \mathrm{s}$ and $\sim 32 \mathrm{~F} / \mathrm{g}$ at $50 \mathrm{mV} / \mathrm{s}$, whereas the capacitance of the porearray GP and CNF equivalents dropped to $\sim 1$ and $\sim 5 \mathrm{~F} / \mathrm{g}$ at 50 $\mathrm{mV} / \mathrm{s}$, respectively, as shown in the magnified inset of Figure $3 \mathrm{~d}$ (also see Table 1). The electrochemical impedance spectroscopy (EIS) data in Figure S1 of the Supporting Information also implied that the pore-array YP structure had the lowest chargetransfer resistance, which positively contributed to its comparatively high performance.

Electrode behavior as a function of the variations in the electrochemically inactive components (SP and CMC) was then investigated using the best-performing pore-array YP electrode, with the intention of minimizing the parasitic inactive fraction. Figure $4 a-c$ shows a series of SEM images for the surface of pore-array YP electrodes. As the inactive component reduced progressively from 20 to $5 \mathrm{wt} \%$, the YP fraction increased correspondingly to $95 \mathrm{wt} \%$, the typical pore diameter increased from $\sim 10$ to $\sim 30 \mu \mathrm{m}$, and the pore density decreased from $\sim 700$ to $\sim 300 \mathrm{~mm}^{-2}$ because of the increased fraction of relatively large YP particulate. The corresponding electrode cross-sections (Figure $4 \mathrm{~d}-\mathrm{f}$ ) show that the directional pore channels of $\sim 20$ 

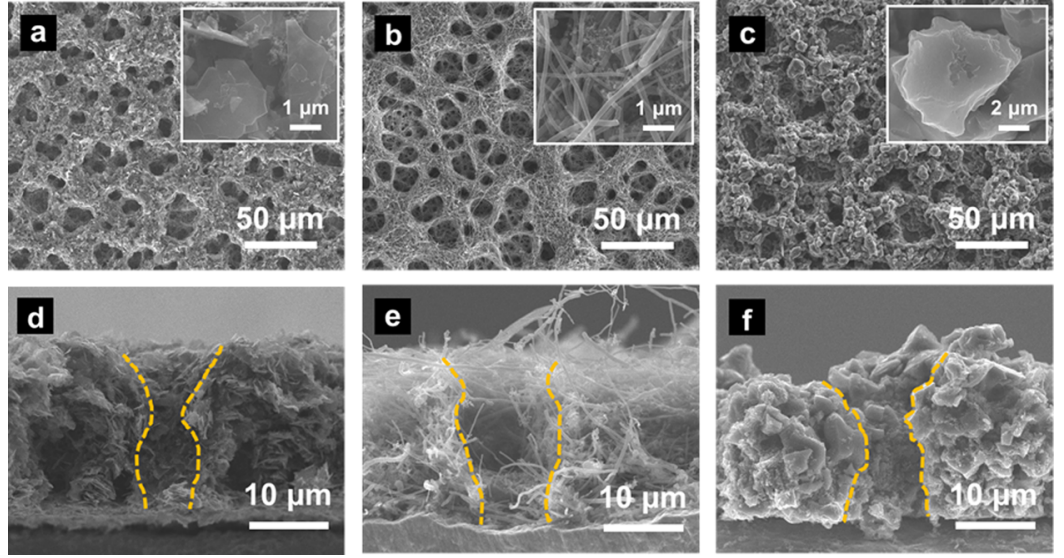

Figure 2. SEM images of the surface of the pore-array electrodes based on (a) GP, (b) CNF, and (c) YP. Each of the inset micrographs magnifies the active carbon material. $(\mathrm{d}-\mathrm{f})$ Corresponding electrode cross-sections. The yellow dotted lines indicate a directional pore channel from the electrode surface to the current collector.

Table 1. Summary of the Pore-Array Electrodes Based on GP, CNF, and YP

\begin{tabular}{ccccccc} 
& & & \multicolumn{4}{c}{ capacitance $(\mathrm{F} / \mathrm{g})$} \\
\cline { 4 - 7 } active materials & thickness $(\mu \mathrm{m})$ & loading mass $\left(\mathrm{mg} / \mathrm{cm}^{2}\right)$ & $0.05 \mathrm{mV} / \mathrm{s}$ & $1 \mathrm{mV} / \mathrm{s}$ & \multicolumn{1}{c}{$10 \mathrm{mV} / \mathrm{s}$} & $50 \mathrm{mV} / \mathrm{s}$ \\
GP & $20 \pm 2$ & $1.23 \pm 0.03$ & 17.6 & 7.1 & 2.9 & 1.1 \\
CNF & $20 \pm 3$ & $1.23 \pm 0.02$ & 25.6 & 8.9 & 5.9 & 4.7 \\
YP & $20 \pm 3$ & $1.25 \pm 0.05$ & 62.1 & 58.8 & 47.6 & 31.6 \\
\hline
\end{tabular}
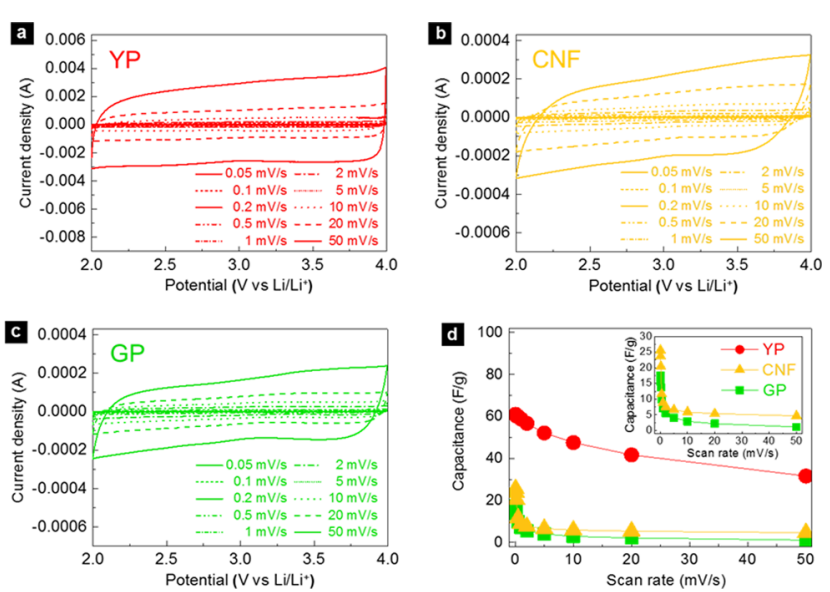

Figure 3. $\mathrm{CV}$ profiles at the increasing scan rate in the potential range of 2.0-4.0 V (vs $\left.\mathrm{Li} / \mathrm{Li}^{+}\right)$for pore-array electrodes based on (a) YP, (b) $\mathrm{CNF}$, and (c) GP. (d) Corresponding capacitance profiles with an inset that magnifies the capacitance plots for the pore-array GP and CNF electrodes.

$\mu \mathrm{m}$ depth were again maintained "deep" into the electrode to the current collector.

Figure 5a shows the corresponding electrode-specific capacitance as a function of the inactive fraction estimated from the CV data (see Figure S2 in the Supporting Information). As the YP fraction increased to $95 \mathrm{wt} \%$ (and the inactive component fraction reduced correspondingly to $5 \mathrm{wt} \%$ ), capacitance increased progressively at all rates. Note that the capacitance was estimated using the entire electrode mass including YP, SP, and CMC, as given in Table 2. At 5 wt \% inactive additives, the capacitance was $\sim 105 \mathrm{~F} / \mathrm{g}$ at $0.05 \mathrm{mV} / \mathrm{s}$ and $\sim 50 \mathrm{~F} / \mathrm{g}$ at $50 \mathrm{mV} / \mathrm{s}$. In Figure $5 \mathrm{~b}$, the $95: 3: 2$ electrode formulation had a higher capacity of $\sim 66 \mathrm{mAh} / \mathrm{g}$ at $10 \mathrm{~mA} / \mathrm{g}$ and $\sim 40 \mathrm{mAh} / \mathrm{g}$ at $2000 \mathrm{~mA} / \mathrm{g}$ that is comparable with or higher

than other synthesized activated carbon materials. ${ }^{10,27-29}$ Figure $5 \mathrm{c}$ displays the galvanostatic capacity profiles at $100 \mathrm{~mA} / \mathrm{g}$ where the pore-array YP electrode with minimum inactive additives ( $\leq 5 \mathrm{wt} \%$ ) sustained a stable capacity of $\sim 55 \mathrm{mAh} / \mathrm{g}$ up to 500 cycles, representing $\sim 100 \%$ capacity retention (compared with the first discharge capacity), while the 90:5:5 and 80:10:10 formulation had capacities reduced to $\sim 50$ and $\sim 40 \mathrm{mAh} / \mathrm{g}$, respectively. All of the YP-based electrodes had $\sim 100 \%$ Coulombic efficiency after 500 cycles (inset of Figure 5c).

To investigate the influence of the pore array on the electrode performance specifically, a nonporous YP electrode was prepared by slurry casting using the same 95:3:2 electrode formulation (denoted as "conventional"), as shown in Figure $\mathrm{S} 3 \mathrm{~b}$ of the Supporting Information. Figure S3c shows the gravimetric discharge capacity profiles of both electrode types in the current density range of $10-2000 \mathrm{~mA} / \mathrm{g}$ (see electrode details in Table S1 of the Supporting Information).

At relatively low rates of $10-50 \mathrm{~mA} / \mathrm{g}$, the electrode structures delivered almost identical capacities, suggesting that the pore-array structure made no marked contribution to the electrode kinetics and there was sufficient time for ions to transport throughout the electrode to all of the active surfaces. However, a difference in deliverable capacity became progressively more marked as the current density increased to 2000 $\mathrm{mA} / \mathrm{g}$. Eventually, the pore-array YP electrode had an approximately $70 \%$ higher discharge capacity. Volumetric discharge capacity in Figure S3d further supported the performance benefit of the pore-array electrode at increasing rates, where volumetric capacity was re-estimated based on the mass and thickness of electrodes (see Table S1). At $10 \mathrm{~mA} / \mathrm{g}$, the conventional electrode had a slightly improved capacity because the electrode was comparatively dense. However, at $2000 \mathrm{~mA} / \mathrm{g}$, the pore-array electrode facilitated Li mobility and outperformed the conventional electrode in volumetric capacity, even though it had a higher pore fraction. 

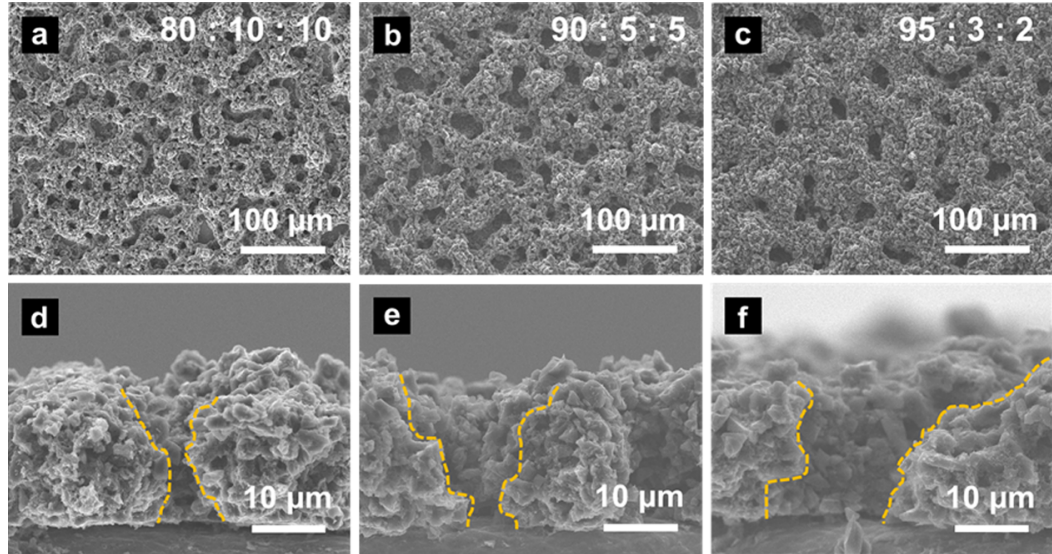

Figure 4. SEM images of the surface of the pore-array electrodes with fractions of YP/SP/CMC in the mass ratios of (a) 80:10:10, (b) 90:5:5, and (c) 95:3:2. (d-f) Corresponding electrode cross-sections. The yellow dotted lines indicate the through-thickness pore channels.
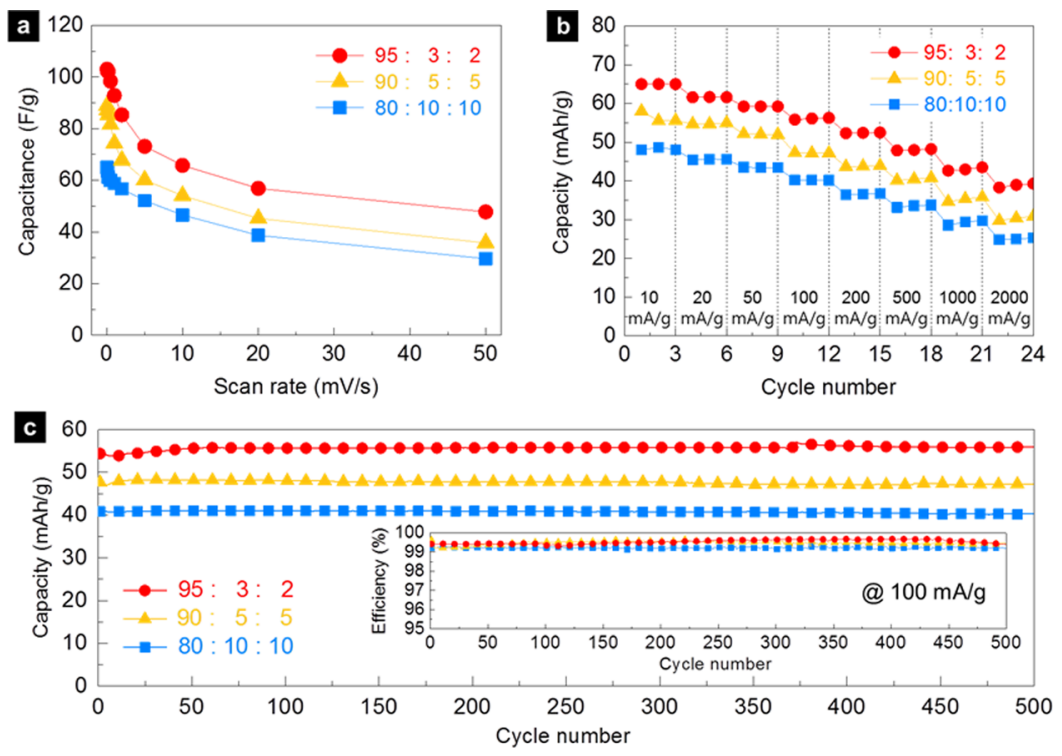

Figure 5. (a) Capacitance data for the pore-array YP electrodes with controlled fractions of inactive components at increasing scan rates in the potential range of $2.0-4.0 \mathrm{~V}\left(\mathrm{vs} \mathrm{Li} / \mathrm{Li}^{+}\right)$. (b) Corresponding gravimetric discharge capacity plots at increasing charge/discharge current densities in the potential range of $2.0-4.0 \mathrm{~V}\left(\mathrm{vs} \mathrm{Li} / \mathrm{Li}^{+}\right)$. (c) Galvanostatic discharge profiles at a constant current density of $100 \mathrm{~mA} / \mathrm{g}$ in the voltage window of $2.0-$ $4.0 \mathrm{~V}\left(\mathrm{vs} \mathrm{Li} / \mathrm{Li}^{+}\right)$and the corresponding Coulombic efficiency (inset).

\section{Table 2. Summary of the Pore-Array YP Electrodes with Differing Inactive Additives}

\begin{tabular}{|c|c|c|c|c|c|c|}
\hline \multirow[b]{2}{*}{ formulation (YP/SP/CMC) } & \multirow[b]{2}{*}{ thickness $(\mu \mathrm{m})$} & \multirow[b]{2}{*}{ loading mass $\left(\mathrm{mg} / \mathrm{cm}^{2}\right)$} & \multicolumn{4}{|c|}{ capacity $(\mathrm{mAh} / \mathrm{g})$} \\
\hline & & & $10 \mathrm{~mA} / \mathrm{g}$ & $100 \mathrm{~mA} / \mathrm{g}$ & $1 \mathrm{~mA} / \mathrm{g}$ & $2 \mathrm{~mA} / \mathrm{g}$ \\
\hline $95: 3: 2$ & $20 \pm 4$ & $1.28 \pm 0.03$ & 65.6 & 56.3 & 44.6 & 40.3 \\
\hline $90: 5: 5$ & $21 \pm 3$ & $1.26 \pm 0.04$ & 56.5 & 47.2 & 36.1 & 30.7 \\
\hline $80: 10: 10$ & $20 \pm 3$ & $1.25 \pm 0.05$ & 48.7 & 40.2 & 30.2 & 26.8 \\
\hline
\end{tabular}

Table 3. Summary of the LICPerformance on Varying the LTO/YP Mass Ratio

\begin{tabular}{|c|c|c|c|c|c|c|}
\hline \multirow[b]{2}{*}{ mass ratio (LTO/YP) } & \multicolumn{2}{|c|}{ loading mass $\left(\mathrm{mg} / \mathrm{cm}^{2}\right)$} & \multicolumn{2}{|c|}{ thickness $(\mu \mathrm{m})$} & \multirow[b]{2}{*}{ energy @0.1 C (Wh/kg) } & \multirow[b]{2}{*}{ power@450 C (W/kg) } \\
\hline & LTO & YP & LTO & YP & & \\
\hline $1: 1$ & $1.52 \pm 0.02$ & $1.53 \pm 0.03$ & 10 & 20 & 21 & 2000 \\
\hline $1: 2$ & $1.52 \pm 0.01$ & $3.03 \pm 0.04$ & 10 & 35 & 32 & 5000 \\
\hline $1: 3$ & $1.53 \pm 0.02$ & $4.58 \pm 0.03$ & 10 & 50 & 43 & 7000 \\
\hline $1: 4$ & $1.52 \pm 0.01$ & $6.05 \pm 0.04$ & 10 & 65 & 50 & 9300 \\
\hline $1: 5$ & $1.52 \pm 0.03$ & $7.61 \pm 0.05$ & 10 & 80 & 52 & 9900 \\
\hline
\end{tabular}

The potential of a carbon-based pore-array positive electrode in a LIC configuration was investigated by pairing it with a spray- printed LTO negative electrode, as depicted in the schematic of a coin-type LIC cell in Figure S4 (also see the spray-printed 

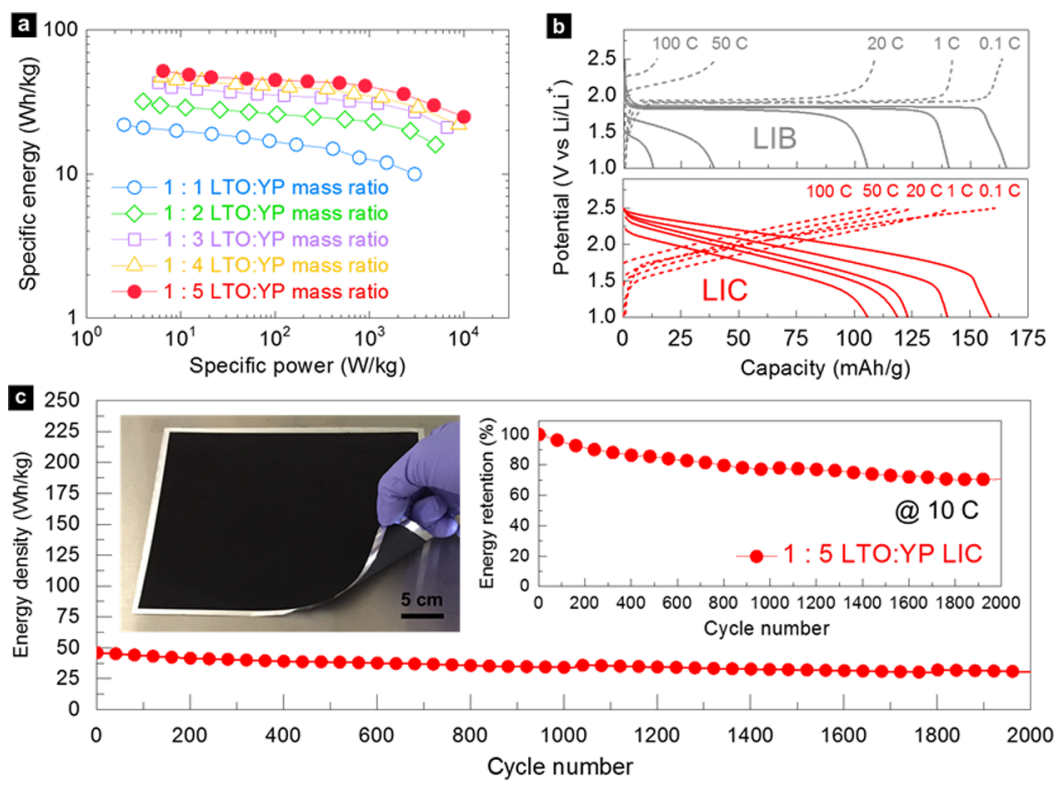

Figure 6. (a) Ragone plots of pore-array LICs as a function of LTO/YP mass ratios from 1:1 to 1:5. (b) Comparative charge/discharge profiles for a conventional LTO/LFP LIB and a pore-array LTO/YP LIC at increasing rates of $0.1-100 \mathrm{C}$ in the voltage window of $1.0-2.5 \mathrm{~V}\left(\mathrm{vs} \mathrm{Li} / \mathrm{Li}{ }^{+}\right) .(\mathrm{c})$ Galvanostatic discharge energy density plot at $10 \mathrm{C}$ in the voltage window of $1.0-2.5 \mathrm{~V}\left(\mathrm{vs} \mathrm{Li} / \mathrm{Li}^{+}\right)$for a 1:5 LTO/YP LIC. The right-hand inset shows the corresponding energy density retention after 2000 cycles. A photograph in the left-hand inset presents an A5-scale double-sided pore-array YP electrode.

LTO performance in Figure S5 and Table S2 of the Supporting Information). Spinel-type LTO is considered promising for LIC applications ${ }^{30,31}$ because its approximately zero-strain lithiuminsertion behavior supports stable capacity delivery even at ultrafast charging rates ( $>10 \mathrm{C}$ ) and during continuous cycling ( $>500$ cycles). In addition, LTO can be utilized without the need for a time-consuming prelithiation step.

A LTO/YP mass ratio in the range $1: 1$ to $1: 5$ was then investigated in a LIC configuration. Here, a $10 \mu \mathrm{m}$ thick LTO negative electrode was fixed, and the YP-based positive electrode weight and the corresponding thickness was varied, from 20 to $80 \mu \mathrm{m}$ (see Table 3 and SEM images in Figure S6 of the Supporting Information). The relatively thin LTO electrodes were chosen to prioritize high power performance rather than volumetric energy density. Figure 6a shows the discharge Ragone plots at various charge/discharge rates for LTO-YP LICs as a function of the LTO/YP mass ratio up to 1:5. The specific power $P$ and energy density $E$ were estimated using $P$ $[\mathrm{W}]=V \times i / m$ and $E[\mathrm{Wh}]=P \times t,,^{32-34}$ where $V$ is the average cell potential $[\mathrm{V}]$ between the lowest and highest cut-off potential, $i$ is the obtained current [A], $m$ is the total weight of both anode and cathode electrodes including LTO, YP, SP, and $\mathrm{CMC}$, and $t$ is the discharge time [h]. As the LTO/YP mass ratio increased from $1: 1$ to $1: 5$, specific energy and power density increased progressively, with the 1:5 LTO/YP arrangement having a specific energy density of $\sim 52 \mathrm{Wh} / \mathrm{kg}$ at $\sim 0.1 \mathrm{C}$ and a specific power density of $\sim 9900 \mathrm{~W} / \mathrm{kg}$ at $\sim 450 \mathrm{C}$ (also see the trend in volumetric Ragone profiles in Figure S7 of the Supporting Information). At 1:6 LTO/YP, the power performance started to reduce to $7500 \mathrm{~W} / \mathrm{kg}$ at $\sim 450 \mathrm{C}$ (see comparative Ragone plots in Figure S8 of the Supporting Information).

The rate capability of the optimized LIC cell was compared with that of a LIB formulated with a 1:1 LTO/LFP mass ratio that had the best rate capability in our previous and other studies. $^{21,22}$ For these LIB configurations, LTO and LFP electrodes were prepared by the identical spray-printing process using a suspension formulated with a 95:3:2 LTO (or LFP)/SP/ CMC mass ratio suspended in a 70:30 DI/IPA bisolvent that was intended to avoid any pore self-assembly (see half-cell performances of each of LTO and LFP electrodes in Figure S5 and Table S2 of the Supporting Information). Figure $6 \mathrm{~b}$ shows the comparative gravimetric charge/discharge plots for the LIB (the upper gray plots) and LIC (the lower red plots) in the rate range of $0.1-100 \mathrm{C}$, noting that performances of both the LIB and LIC were estimated based on the total mass of the LTO anodes, i.e., including LTO, SP, and CMC. At 0.1C, the LIC and the LIB had similar capacities of $\sim 165 \mathrm{mAh} / \mathrm{g}$ and $\sim 155 \mathrm{mAh} / \mathrm{g}$, respectively. However, as the $\mathrm{C}$-rate increased up to $100 \mathrm{C}$, the difference in capacity between the LIC and LIB became more marked. At $100 \mathrm{C}$, the LIC had a discharge capacity of $\sim 110$ $\mathrm{mAh} / \mathrm{g}$, sustaining $\sim 75 \%$ of its discharge capacity at $0.1 \mathrm{C}$, while the LIB capacity had dropped to $\sim 10 \mathrm{mAh} / \mathrm{g}$, one order of magnitude lower than that of the LIC at the same rate.

The cycle life of the 1:5 LTO/YP LIC cell was investigated at a constant rate of $10 \mathrm{C}$ (Figure $6 \mathrm{c}$ ). As the charge/discharge cycle progressed to the $500^{\text {th }}$ cycle, the energy density declined relatively rapidly, delivering $\sim 85 \%$ of the initial energy density $(\sim 45 \mathrm{Wh} / \mathrm{kg}$ at the first cycle). However, the reduction was then less marked so that even after 2000 cycles, the energy density was $\sim 32 \mathrm{Wh} / \mathrm{kg}(\sim 70 \%$ energy density retention $)$, as shown in the right-hand inset of Figure $6 \mathrm{c}$.

A photograph in the left-hand inset (Figure 6c) shows a double-sided pore-array YP electrode over an A5-scale $\mathrm{Al}$ current collector $(20 \mathrm{~cm} \times 15 \mathrm{~cm})$. It is worth noting that scalable, double-sided coating is essential for the manufacture of multiple cell packs for high-energy-storage applications including electric cars and grid energy storage. Further, the ability to locate the pore-array pore structure selectively on any desired region of the electrode may be useful in achieving an attractive balance between gravimetric and volumetric capacity (or power and capacity) for large-area electrodes (see a photo of 

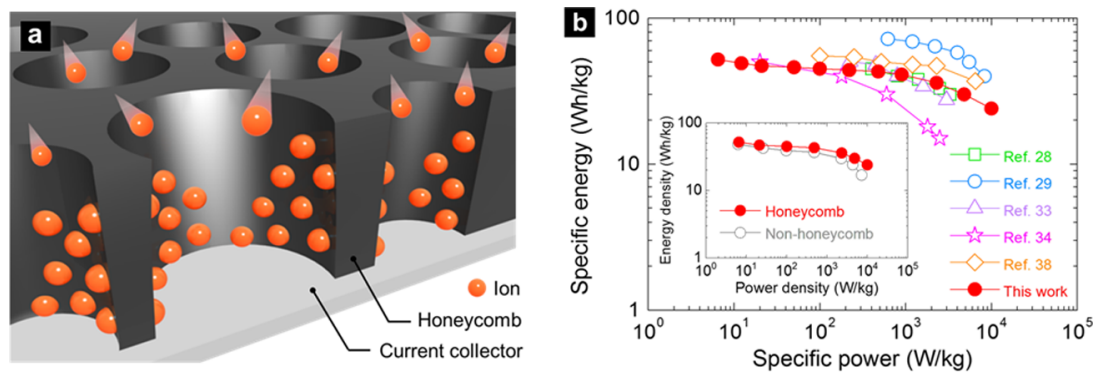

Figure 7. (a) Schematic diagram depicting the structural advantage of the through-thickness pore-array channels in electrochemical LIC performance by promoting lithium-ion mobility in the critical through-thickness direction. (b) Comparative Ragone profiles. The inset shows Ragone plots for the 1:5 LTO/YP LIC devices with and without the pore-array YP.

patterning the letters "OX" on one side of the pore-array YP electrode in Figure S9 of the Supporting Information). For example, if all of the areas of electrodes comprised the pore-array structures only, outstanding gravimetric capacity would be realized at ultrafast charging rates but only with relatively poor volumetric performance at slow rates. However, if the pore-array structure can be designed and assembled only in the desired area, e.g., at pouch cell corners that are distant from the current collector tabs where active material utilization or ion distribution is often relatively poor at ultrafast rates, ${ }^{35-37}$ more balanced power and capacity performance might be achieved.

Overall, the through-thickness pore-array architecture can be expected to facilitate the dispersion of active ions to all of the accessible active surface areas within the electrode, as depicted schematically in Figure 7a. For example, the LIC constructed with pore-array electrodes provided an approximately $40 \%$ improvement in power capability over the identical LIC arrangement with nonporous, conventional electrodes at 400 C: a specific power density of $\sim 9900 \mathrm{~W} / \mathrm{kg}$ at $\sim 24 \mathrm{Wh} / \mathrm{kg}$ for the pore-array LIC (red) and a power density of $\sim 7200 \mathrm{~W} / \mathrm{kg}$ at $\sim 17 \mathrm{Wh} / \mathrm{kg}$ for the conventional LIC (gray), as shown in the comparative Ragone curves in the inset of Figure $7 \mathrm{~b}$. The porearray-based LIC is also compared with other LIC cells in Figure $7 \mathrm{~b}$. At relatively slow charging rates, the energy performance was comparable with other LTO/activated carbon-based LIC configurations. However, at ultrafast charging rates $(\geq 100 \mathrm{C})$, the pore-array LIC outperformed similar configurations (see detailed comparison in Table S3 of the Supporting Information), noting that many of the competing performance data relied on conductive enhancers (e.g., carbon coating or graphene additives) to boost rate capability or utilized higher fractions of parasitic inactive components ( $\geq 20 \mathrm{wt} \%$ ), the weight of which was generally not taken into account in the performance estimation. $^{28,29,33,34,38}$

\section{CONCLUSIONS}

Honeycomb patterns through the thickness of electrochemical electrodes were layer-by-layer self-assembled over large-area current collectors $(\sim 20 \mathrm{~cm} \times 15 \mathrm{~cm})$ using a spray-printing approach. Deposition used an atomized suspension formulated with an optimum 50:50 mixture (by volume) of fugitive DI water and IPA. Initially, the electrochemical capacitance of porearray electrodes as a function of active component types (CNF, GP, and YP) was studied, and, subsequently, the effect of minimizing inactive components (SP and CMC) was investigated in the range of $20-5 \mathrm{wt} \%$. The best-performing porearray YP cathode (5 wt \% inactive fraction) was then coupled with a spray-coated LTO anode to investigate performance in a
LIC arrangement as a function of the YP/LTO mass ratio. A 1:5 LTO/YP combination offered outstanding LIC performance, with an energy density of $\sim 52 \mathrm{Wh} / \mathrm{kg}$ at $0.1 \mathrm{C}$ and a power density of $\sim 10000 \mathrm{~W} / \mathrm{kg}$ at $450 \mathrm{C}$. The through-thickness porearray electrode architecture was particularly advantageous where fast electrode kinetics and promotion of active surface area were required, e.g., up to $400 \mathrm{C}$ charge/discharge rates. Spray printing also facilitated a selective patterning approach that might be used to enhance local ion mobility, such as selected areas in large-area pouch cells that otherwise suffer from "dead zones" of poor material utilization.

\section{EXPERIMENTAL SECTION}

Materials. CNF and LTO were purchased from Sigma Aldrich, U.K.; GP from Thomas Swan \& Co. Ltd., U.K.; YP from Kuraray, Japan; and LFP from Hydro-Québec, Canada.

Spray-Printing Process. For the spray suspensions, active carbon (GP, CNF, or YP), SP, and CMC in various mass ratios were wellblended in a mixture of DI water and IPA using sonication. Although DI water was used to dissolve CMC, the IPA was needed to disperse the carbon materials into aqueous suspension. For the electrode fabrication, an $\mathrm{Al}$ foil was placed on a hot plate $\left(\geq 120^{\circ} \mathrm{C}\right)$. The active carbon-based suspension was pumped to a spray nozzle and, subsequently, atomized in a spray cone of suspension droplets at a constant air pressure of 0.3 bar, which deposited onto the heated foil continuously as the spray reciprocated over the foil at a constant distance in a preprogrammed path. The spray-printing process was conducted in a well-ventilated fume cupboard.

Electrochemical Tests. The electrochemical behavior of electrodes was examined using coin-type electrochemical cells (CR2032) that were assembled in an Ar-filled glovebox $\left(\mathrm{H}_{2} \mathrm{O}<0.1 \mathrm{ppm}, \mathrm{O}_{2}<0.1\right.$ ppm). For half-cell tests, electrodes were coupled with Li foils ( $99.9 \%$ trace metals basis, MTI Corporation) that were used as a counter/ reference electrode. For both half-cells and full LICs, full LIBs, negative and positive electrodes were electrically separated by a polyethylene separator (Cellgard 2400) soaked into a $1 \mathrm{M} \mathrm{LiPF}_{6}$ electrolyte solution in a 1:1 mixture (by volume) of ethylene carbonate and dimethyl carbonate (Merck). LIC cells were assembled without a prelithiation process. All charge/discharge tests were performed at room temperature using an Arbin BT2000 cycler. CV and EIS measurements were carried out using a Gamry 600 potentiostat. The theoretical capacity of both LTO and LFP was assumed to be $\sim 175 \mathrm{mAh} / \mathrm{g}^{22,30,31}$

\section{ASSOCIATED CONTENT}

\section{S Supporting Information}

The Supporting Information is available free of charge on the ACS Publications website at DOI: 10.1021/acsami.9b14478.

Nyquist plots of pore-array electrodes as a function of the active material type, $\mathrm{CV}$ profiles for the pore-array YP electrodes according to a change in inactive components, comparative capacity profiles for the YP-based pore-array 
and conventional electrodes, schematic diagram of the coin-type LIC cell, performances of spray-printed LTO and LFP electrodes, SEM images of the $80 \mu \mathrm{m}$ YP porearray electrode, volumetric Ragone plots of pore-array LICs, LIC performance as a function of LTO/YP mass ratios and comparative LIC performances, and a photo of a selectively patterned YP pore-array electrode (PDF)

\section{AUTHOR INFORMATION}

\section{Corresponding Author}

*E-mail: sangho.lee@materials.ox.ac.uk.

\section{ORCID}

Sang Ho Lee: 0000-0002-2546-5598

\section{Notes}

The authors declare no competing financial interest.

\section{ACKNOWLEDGMENTS}

This work was supported by U.K. Engineering and Physical Science Research Council grant EP/M009394 (ELEVATE) and by Innovate U.K., grant number 102655 project "ALICE Advanced Lithium Ion Capacitors and Electrodes”.

\section{REFERENCES}

(1) Lee, S. H.; Kim, W. B. Stripe- or Square-Patterned Arrays of Tin Dioxide Nanowires for Use in Lithium-Ion Battery Electrodes. J. Power Sources 2016, 307, 38-44.

(2) Li, M.; Lu, J.; Chen, Z.; Amine, K. 30 Years of Lithium-Ion Batteries. Adv. Mater. 2018, 30, No. 1800561

(3) Winter, M.; Barnett, B.; Xu, K. Before Li Ion Batteries. Chem. Rev. 2018, 118, 11433-11456.

(4) Lee, S. H.; Jo, Y.-R.; Noh, Y.; Kim, B.-J.; Kim, W. B. Stripe- or Square-Patterned Arrays of Tin Dioxide Nanowires for Use in LithiumIon Battery Electrodes. J. Power Sources 2017, 367, 1-7.

(5) Chen, L.-F.; Lu, Y.; Yu, L.; Lou, X. W. Designed Formation of Hollow Particle-Based Nitrogen-Doped Carbon Nanofibers for HighPerformance Supercapacitors. Energy Environ. Sci. 2017, 10, 17771783.

(6) Yang, H.; Kannappan, S.; Pandian, A. S.; Jang, J.-H.; Lee, Y. S.; Lu, W. Graphene Supercapacitor with both High Power and Energy Density. Nanotechnology 2017, 28, No. 445401.

(7) Jung, H.-G.; Venugopal, N.; Scrosati, B.; Sun, Y.-K. A High Energy and Power Density Hybrid Supercapacitor Based on an Advanced Carbon-Coated $\mathrm{Li}_{4} \mathrm{Ti}_{5} \mathrm{O}_{12}$ Electrode. J. Power Sources 2013, 221, 266271.

(8) Lu, Q.; Lu, B.; Chen, M.; Wang, X.; Xing, T.; Liu, M.; Wang, X. Porous Activated Carbon Derived from Chinese-Chive for High Energy Hybrid Lithium-Ion Capacitor. J. Power Sources 2018, 398, 128-136.

(9) Zhao, E.; Qin, C.; Jung, H.-R.; Berdichevsky, G.; Nese, A.; Marder, S.; Yushin, G. Lithium Titanate Confined in Carbon Nanopores for Asymmetric Supercapacitors. ACS Nano 2016, 10, 3977-3987.

(10) Puthusseri, D.; Aravindan, V.; Madhavi, S.; Ogale, S. Improving the Energy Density of Li-Ion Capacitors Using Polymer-Derived Porous Carbons as Cathode. Electrochim. Acta 2014, 130, 766-770.

(11) Chen, Y.; Shi, L.; Guo, S.; Yuan, Q.; Chen, X.; Zhou, J.; Song, H. A General Strategy towards Carbon Nanosheets from Triblock Polymers as High-Rate Anode Materials for Lithium and Sodium Ion Batteries. J. Mater. Chem. A 2017, 5, 19866-19874.

(12) Xiao, J.; Mei, D.; Li, X.; Xu, W.; Wang, D.; Graff, G. L.; Bennett, W. D.; Nie, Z.; Saraf, L. V.; Aksay, I. A.; Liu, J.; Zhang, J.-G. Hierarchically Porous Graphene as a Lithium-Air Battery Electrode. Nano Lett. 2011, 11, 5071-5078.

(13) Pearse, A.; Schmitt, T.; Sahadeo, E.; Stewart, D. M.; Kozen, A.; Gerasopoulos, K.; Talin, A. A.; Lee, S. B.; Rubloff, G. W.; Gregorczyk, K. E. Three-Dimensional Solid-State Lithium-Ion Batteries Fabricated by Conformal Vapor-Phase Chemistry. ACS Nano 2018, 12, 42864294.
(14) Sander, J. S.; Erb, R. M.; Li, L.; Gurijala, A.; Chiang, Y.-M. HighPerformance Battery Electrodes via Magnetic Templating. Nat. Energy 2016, 1, No. 16099.

(15) Lee, S. H.; Huang, C.; Grant, P. S. Layer-by-Layer Printing of Multi-Layered Heterostructures Using $\mathrm{Li}_{4} \mathrm{Ti}_{5} \mathrm{O}_{12}$ and $\mathrm{Si}$ for High Power Li-Ion Storage. Nano Energy 2019, 61, 96-103.

(16) Cheng, C.; Drummond, R.; Duncan, S. R.; Grant, P. S. MicroScale Graded Electrodes for Improved Dynamic and Cycling Performance of Li-Ion Batteries. J. Power Sources 2019, 413, 59-67.

(17) Huang, C.; Young, N. P.; Zhang, J.; Snaith, H. J.; Grant, P. S. A Two Layer Electrode Structure for Improved $\mathrm{Li}$ Ion Diffusion and Volumetric Capacity in Li Ion Batteries. Nano Energy 2017, 31, 377395.

(18) Huang, C.; Kim, A.; Chung, D. J.; Park, E.; Young, N. P.; Jurkschat, K.; Kim, H.; Grant, P. S. Multiscale Engineered $\mathrm{Si} / \mathrm{SiO}_{x}$ Nanocomposite Electrodes for Lithium-Ion Batteries Using Layer-byLayer Spray Deposition. ACS Appl. Mater. Interfaces 2018, 10, 1562415633.

(19) Fu, C.; Mahadevegowda, A.; Grant, P. S. Production of Hollow and Porous $\mathrm{Fe}_{2} \mathrm{O}_{3}$ from Industrial Mill Scale and Its Potential for LargeScale Electrochemical Energy Storage Applications. J. Mater. Chem. A 2016, 4, 2597-2604.

(20) Lee, S. H.; Mahadevegowda, A.; Huang, C.; Evans, J. D.; Grant, P. S. Spray Printing of Self-Assembled Porous Structures for High Power Battery Electrodes. J. Mater. Chem. A 2018, 6, 13133-13141.

(21) Lee, S. H.; Li, K.; Huang, C.; Evans, J. D.; Grant, P. S. SprayPrinted and Self-Assembled Honeycomb Electrodes of SiliconDecorated Carbon Nanofibers for Li-Ion Batteries. ACS Appl. Mater. Interfaces 2019, 11, 603-612.

(22) Lee, S. H.; Huang, C.; Johnston, C.; Grant, P. S. Spray printing and Optimization of Anodes and Cathodes for High Performance LiIon Batteries. Electrochim. Acta 2018, 292, 546-557.

(23) Li, B.; Zhang, H.; Wang, D.; Lv, H.; Zhang, C. Agricultural Waste-Derived Activated Carbon for High Performance Lithium-Ion Capacitors. RSC Adv. 2017, 7, 37923-37928.

(24) Ding, J.; Wang, H.; Li, Z.; Cui, K.; Karpuzov, D.; Tan, X.; Kohandehghan, A.; Mitlin, D. Peanut Shell Hybrid Sodium Ion Capacitor with Extreme Energy-Power Rivals Lithium Ion Capacitors. Energy Environ. Sci. 2015, 8, 941-955.

(25) Huang, C.; Zhang, J.; Snaith, H. J.; Grant, P. S. Engineering the Membrane/Electrode Interface To Improve the Performance of SolidState Supercapacitors. ACS Appl. Mater. Interfaces 2016, 8, 2075620765.

(26) Huang, C.; Zhang, J.; Young, N. P.; Snaith, H. J.; Grant, P. S. Solid-state Supercapacitors with Rationally Designed Heterogeneous Electrodes Fabricated by Large Area Spray Processing for Wearable Energy Storage Applications. Sci. Rep. 2016, 6, No. 25684.

(27) Jain, A.; Aravindan, V.; Jayaraman, S.; Kumar, P. S.; Balasubramanian, R.; Ramakrishna, S.; Madhavi, S.; Srinivasan, M. P. Activated Carbons Derived from Coconut Shells as High Energy Density Cathode Material for Li-Ion Capacitors. Sci. Rep. 2013, 3, No. 3002.

(28) Aravindan, V.; Mhamane, D.; Ling, W. C.; Ogale, S.; Madhavi, S. Nonaqueous Lithium-Ion Capacitors with High Energy Densities using Trigol-Reduced Graphene Oxide Nanosheets as Cathode-Active Material. ChemSusChem 2013, 6, 2240-2244.

(29) Ye, L.; Liang, Q.; Lei, Y.; Yu, X.; Han, C.; Shen, W.; Huang, Z.-H.; Kang, F.; Yang, Q.-H. A High Performance Li-Ion Capacitor Constructed with $\mathrm{Li}_{4} \mathrm{Ti}_{5} \mathrm{O}_{12} / \mathrm{C}$ Hybrid and Porous Graphene Macroform. J. Power Sources 2015, 282, 174-178.

(30) Sun, X.; Radovanovic, P. V.; Cui, B. Advances in Spinel $\mathrm{Li}_{4} \mathrm{Ti}_{5} \mathrm{O}_{12}$ Anode Materials for Lithium-Ion Batteries. New J. Chem. 2015, 39, 38 63.

(31) Han, C.; He, Y.-B.; Liu, M.; Li, B.; Yang, Q.-H.; Wong, C.-P.; Kang, F. A review of gassing behavior in $\mathrm{Li}_{4} \mathrm{Ti}_{5} \mathrm{O}_{12}$-based lithium ion batteries. J. Mater. Chem. A 2017, 5, 6368-6381.

(32) Dong, S.; Li, H.; Wang, J.; Zhang, X.; Ji, X. Improved Flexible LiIon Hybrid Capacitors: Techniques for Superior Stability. Nano Res. 2017, 10, 4448-4456. 
(33) Xu, H.; Hu, X.; Sun, Y.; Luo, W.; Chen, C.; Liu, Y.; Huang, Y. Highly Porous $\mathrm{Li}_{4} \mathrm{Ti}_{5} \mathrm{O}_{12} / \mathrm{C}$ Nanofibers for Ultrafast Electrochemical Energy Storage. Nano Energy 2014, 10, 163-171.

(34) Kim, H.; Park, K.-Y.; Cho, M.-Y.; Kim, M.-H.; Hong, J.; Jung, S.K.; Roh, K. C.; Kang, K. High-Performance Hybrid Supercapacitor Based on Graphene-Wrapped $\mathrm{Li}_{4} \mathrm{Ti}_{5} \mathrm{O}_{12}$ and Activated Carbon. ChemElectroChem 2014, 1, 125-130.

(35) Hosseinzadeh, E.; Genieser, R.; Worwood, D.; Barai, A.; Marco, J.; Jennings, P. A Systematic Approach for Electrochemical-Thermal Modelling of a Large Format Lithium-Ion Battery for Electric Vehicle Application. J. Power Sources 2018, 382, 77-94.

(36) Bazinski, S. J.; Wang, X. Thermal Effect of Cooling the Cathode Grid Tabs of a Lithium-Ion Pouch Cell. J. Electrochem. Soc. 2014, 161, A2168-A2174.

(37) Cai, L.; Ana, K.; Feng, Z.; Liang, C.; Harris, S. J. In-Situ Observation of Inhomogeneous Degradation in Large Format Li-Ion Cells by Neutron Diffraction. J. Power Sources 2013, 236, 163-168.

(38) Lei, Y.; Huang, Z.-H.; Yang, Y.; Shen, W.; Zheng, Y.; Sun, H.; Kang, F. Porous Mesocarbon Microbeads with Graphitic Shells: Constructing a High-Rate, High-Capacity Cathode for Hybrid Supercapacitor. Sci. Rep. 2013, 3, No. 2477. 